\section{AS COMPETÊNCIAS PEDAGÓGICAS NA FORMAÇÃO DOCENTE E PROFISSIONAL DO PEDAGOGO}

\section{THE PEDAGOGICAL COMPETENCES IN THE TEACHER AND PROFESSIONAL FORMATION OF THE PEDAGOGUE}

Rita de Cássia Nascimento Silva ${ }^{1, *}$ / Marcos Antonio Vanderlei Silva ${ }^{2} /$ Charles Cardoso Santana ${ }^{3}$

\section{INTRODUÇÃO}

Competência, do Lat. Competentia significa: aptidão; capacidade; faculdade legal de um funcionário ou tribunal para apreciar ou julgar certos pleitos e questões. A palavra Competência foi primeiramente utilizada na idade média para definir aqueles que nos tribunais, tinham o conhecimento para apreciar e julgar determinadas questões. Ao longo do tempo passou a qualificar a pessoa que tem condições de realizar determinado trabalho. Desde Taylor, ser competente se tornou um diferencial no mercado de trabalho. Naquela época, competência estava mais relacionada à habilidade técnica - saber fazer algo bem feito. Com a evolução da administração, competência passou a ser não mais só o saber fazer, mas saber por que fazer e mais, ter vontade de fazer.

Na área de educação e trabalho, Depresbiteris (2001 n.p.) mostra que a palavra competência surgiu no contexto da crise do modelo de organização taylorista/fordista, de mundialização da economia, de exacerbação da competição nos mercados e de demandas de melhoria da qualidade dos produtos e de flexibilização dos processos de produção e de trabalho. Neste contexto de crise, e tendo por base um forte incremento da escolarização dos jovens, as empresas passam a usar e adaptar as aquisições individuais da formação, sobretudo escolar, em função das suas exigências. A aprendizagem passa a ser orientada para a ação e a avaliação das competências baseia-se em resultados observáveis.

\section{RESUMO}

O objetivo do presente trabalho foi estudar descritivamente as competências pedagógicas, com base nas preconizados por Perrenoud (2000), a partir da formação docente e profissional do pedagogo no lócus de trabalho. O campo de pesquisa abrangeu uma unidade de ensino do município de Barreiras, figurando como entrevistados os professores com formação em pedagogia. Dentro das condições trabalhadas pelo contorno metodológico, pode-se inferir a existência de falta de envolvimento com projetos de extensão além de o corpo docente não apresentar interação nos planejamentos comuns com os colegas de equipe e com a escola. Não obstante, um ponto forte que se destaca na análise coletiva das competências é a "média dificuldade" em administrar a progressão das aprendizagens.

Palavras-chave: Saberes. Formação docente. Competência pedagógica.

\section{ABSTRACT}

The aim of this study was descriptively pedagogical competences, based on recommended by Perrenoud (2000), from the teaching and training of in workplace. The research field included a teaching unit of the Barreiras, appearing as interviewed teachers with training in pedagogy. Considering the methodological process, it is inferred that there is a lack of involvement of the teachers with extension projects besides not having interaction in the common plans with the teammates and with the school. Despite this, a strong point that stands out in the collective analysis of competences is the average difficulty in managing the progression of learning.

Keywords: Knowledge. Teacher training. Pedagogical competence.

Submetido em: 20 de jun. 2018

Aceito em: 06 de nov. 2018

\footnotetext{
${ }^{1}$ Técnica Administrativa - Departamento de Ciências Humanas - Campus IX, Universidade do Estado da Bahia, Barreiras, Bahia - Brasil.

${ }^{2}$ Professor Adjunto - Departamento de Ciências Humanas - Campus IX Universidade do Estado da Bahia, Barreiras, Bahia - Brasil.

${ }^{3}$ Professor - UNIRB, Barreiras, Bahia - Brasil

*E-mail para correspondência: rcbnascimento@uneb.br
}

Rev. ComCiência - dez. 2018, vol. 3, no. 3, p. 90-97 / doi: 10.36112/issn2595-1890.v3i1.p90-97 
com Ciência

Uma revista multidisciplinar
As competências pedagógicas na formação docente e profissional do pedagogo
Perrenoud (2000 p. 14) apresenta dez famílias de competência para ensinar: organizar e dirigir situações de aprendizagens; administrar a progressão de aprendizagem; conceber e fazer evoluir os dispositivos de diferenciação; envolver os alunos em suas aprendizagens e em seu trabalho; trabalhar em equipe; participar da administração da escola; informar e envolver os pais; utilizar novas tecnologias; enfrentar os deveres e os dilemas éticos da profissão; administrar sua própria formação continua. A partir dessa assertiva Pires (2015 n.p.), esclarece que a educação do século XXI deverá permitir ao sujeito construir uma vida cidadã, desenvolver as competências exigidas no mercado de trabalho, e possibilitar uma releitura do processo de ensino aprendizagem, pois Barbosa et al. (2000 p. 64) deixam claro que há um forte consenso quanto a necessidade de formação de professores capazes de assumirem os desafios de grandes mudanças, aptos a enfrentarem a reorganização e seleção de diferentes conteúdos e métodos, ágeis na definição de novos caminhos e familiarizado com a complexidade que caracteriza o mundo do trabalho e suas relações com o sistema educacional.

No âmbito dessa discussão, sobre competências profissionais, necessário se faz destacar Perrenoud (2001 p. 21) onde ele declara que essas são: "Um conjunto diversificado de conhecimento da profissão, de esquemas de ação e de posturas que são mobilizados no exercício do ofício. As competências são, ao mesmo tempo, de ordem cognitiva, afetiva, conativa e prática". Servindo-se dessa premissa o presente estudo teve por objetivo identificar as competências necessárias, a partir das preconizadas por Perrenoud, na formação docente e profissional do pedagogo que atua na Escola Municipal Professora Cleonice Lopes (EMCL), pois o magistério é uma profissão complexa que requer dos professores competências nos planos bio-psico-social-políticopedagógico-cultural (MACEDO, 2002 p.14).

\section{Fundamentação}

Segundo Nunes (2001 p. 27) as pesquisas sobre formação de professores com ênfase na prática docente, no sentido de compreendê-la numa perspectiva articulada entre teoriaprática, datam dos anos 90. A partir destes anos, no Brasil, buscaram-se novos enfoques e paradigmas que pudessem melhor explicar a prática docente e os saberes pedagógicos presentes no conteúdo escolar a ser ensinado e a ser aprendido. Nesta perspectiva ampliou-se o foco de análise para além da sala de aula, resgatando "o papel do professor, destacando a importância de se pensar a formação numa abordagem que vá além do acadêmico, envolvendo o desenvolvimento pessoal, profissional e organizacional da profissão docente".

Dentro dessa linha de pensamento Silveira (2003 p.3), por meio de uma revisão crítica sobre as competências e habilidades pedagógicas, enfatiza que os estudos e pesquisas tem indicado também o valor da formação do professor. Qual formação poderia preparar o sujeito que exerce o ofício de professor em possível profissional que atenda á sua realidade enquanto cidadão e á demanda dos alunos, da sociedade e do mundo do trabalho? Quais as mudanças? Quais as garantias? Assim arriscamos afirmar, que precisamos de aulas que ultrapassem a aprendizagem reducionista dos conteúdos específicos, técni- cos e não passem de raspão pelos saberes essenciais ao homem, como se estes fossem apenas conteúdos obrigatórios. É imprescindível que jovens aprendam com os outros. Mas, para isso é necessário estabelecer a ruptura com o aulismo restrito, com um ensino alienante e alienado, utilizando-se de um discurso e uma prática atualizada: transversalizada, complexa, interdisciplinarizada, integrada aos conteúdos críticos.

Em um estudo centrado nos conceitos de competência Senac (2002) concluiu:

[...] que há duas tendências gerais: uma de definir a competência como potencial de conhecimento, habilidades, atitudes e emoções em condições de serem mobilizadas na resolução dos problemas profissionais; a outra tendência é a de só considerar competência como um output, um resultado final da prática eficiente do trabalho ou da tarefa profissional (SENAC, 2002, p.03).

Correlacionando essa ideia com o efetivo contexto escolar, o pedagogo necessariamente precisa refletir o seu fazer pedagógico sobre três dimensões: "conhecimento na ação, reflexão na ação, e reflexão sobre a ação". Através desse dinâmico processo, compreende-se que haverá notadamente do fazer pedagógico, ou mesmo, uma contribuição para a consolidação de práticas significativas que estejam voltadas para o aluno (SOARES, 1996, p.31).

\section{Material e Métodos}

Esta pesquisa é de natureza qualitativa consistindo num estudo de caso, sem fugir, no entanto, do caráter quantitativo para fins de direcionamento conclusivo, onde, neste intento, foi construída uma escala quantitativa 
com Ciência

Uma revista multidisciplinar de dificuldade (descrito adiante). Também se caracteriza por ser aplicada, uma vez que os resultados foram trabalhados na solução dos problemas identificados na realidade corrente.

$O$ estudo foi realizado na Escola Municipal Professora Cleonice Lopes (EMCL), fundada em 1988, localizada à Rua Costa Rica, S/N, no bairro Vila Rica, na cidade de Barreiras. A EMCL atende atualmente a 854 (oitocentos e cinquenta e quatro) alunos distribuídos nos turnos matutino, vespertino e noturno, nas modalidades de ensino: fundamental e EJA (Educação de Jovens e Adultos). Atualmente a escola atende aos bairros/setores Vila Rica, Barreiras I (Pombal) e São Sebastião, que tem uma população estimada de 20.286 habitantes (IBGE, 2017).

A pesquisa foi desenvolvida em duas etapas que se complementaram, sendo a primeira relativa a uma revisão de literatura a respeito do tema a fim de nortear a compreensão da proposta, bem como o processo de problematização e discussão. A segunda etapa foi desenvolvida por meio de uma pesquisa exploratória, na qual se utilizou, para a coleta dos dados, um questionário contendo perguntas abertas e fechadas para que se pudesse penetrar no universo concreto da população envolvida no estudo. Este questionário foi validado através da análise de dois procedimentos, a saber: um a execução do pré-teste, aplicado a uma amostra de caráter semelhante à população alvo, porém, não sendo os sujeitos pertencentes a esta última, acrescido do parecer de dois especialistas na área, que identificaram a coerência deste com os objetivos propostos. Através da comparação dos dados obtidos com estes dois procedimentos pôde-se, então, elaborar o questionário definitivo. Utilizou-se o universo da população alvo que abrangeu um total de 17 professores com formação acadêmica de Pedagogia. O teor do questionário contemplou a busca por informações em dois pontos balizadores: a) informações gerais de formação e b) o desenvolvimento das 10 (dez) competências, baseadas em Perrenoud (2000 p. 14).

Por meio do enfoque dado nesta pesquisa é natural que não se espere um cenário onde todos os professores de uma escola tenham desenvolvido todas as competências. Isso ocorre pois existem diferenças na formação e na experiência de cada professor. É justamente essa diversidade de conhecimentos e de competência profissional que vai caracterizar a equipe de uma unidade escolar e sua necessidade de desenvolvimento profissional, seja em termos da equipe como um todo, seja em termos individuais. A fim de alcançar uma resposta que abranja de forma mais integralizada as tendências dessas competências, por parte do corpo docente, foi desenvolvida uma escala de dificuldades que varia quantitativamente de -17 até 17 , e qualitativamente de "Nenhuma Dificuldade" (G 0)" até "Extrema Dificuldade" (G 4)", preconizada por Silva (2009 p. 41). A variação quantitativa apresentou os extremos no valor de 17 devido ao universo total dos professores entrevistados. Assim, os resultados numéricos se apresentaram como desvios que, algebricamente, representa o total das respostas SIM menos o total das respostas NÃO, indicando os desvios para valores negativos como tendência para um maior grau de dificuldade no desenvolvimento das competências (Gráfico 1).

\section{Resultado e discussão}

No Gráfico 1 encontra-se descrito um "mapa" da carreira de estudo formal dos professores do EMCL. Destaca-se que o ensino público foi a base da formação fundamental, média e superior para o corpo docente nesta pesquisa (Gráfico 1a, 2b e 2c). Dentro desse contexto, Nóvoa (1992) alerta, no entanto, que uma boa graduação é necessária, mas não basta, é essencial atualizar-se sempre. Por isso, de acordo com a oportunidade conjuntural de Barreiras foi observado que em torno de $70 \%$ dos docentes pedagogos investiram na especialização (Gráfico 1d). Pode ser averiguada por meio do Gráfico 2, uma curva crescente de $29,41 \%$ para congressos até 88,23\% para Encontros, a qual revela a importância atribuída por parte dos professores à "formação ao longo da vida", justificada em grande medida, segundo Silva (2002 p. 101), pelas características da sociedade pósmoderna que colocam novas exigências ao saber, ao saber fazer e, sobretudo, ao saber como fazer profissionais.

No entanto, Peres et al. (2013) observou em seu trabalho que, apesar de aproximadamente $90 \%$ dos participantes da pesquisa indicaram a importância e a necessidade da continuidade de estudos, se torna preocupante o dado de que aproximadamente $8 \%$ dos participantes não realizam cursos de formação continuada em função da sobrecarga de trabalho e das condições financeiras desfavoráveis.

Senac (2002, p 3) propalou que há um problema de avaliar a competência, uma vez que a mesma não pode ser mensurável por escalas métricas. Como a competência não trata de conhecimento exato e sim de uma 
com Ciência

Uma revista multidisciplinar

questão humana, ela não pode ser medida pelos sistemas tradicionais de pontuação, e sim por métodos qualitativos de julgamentos, que implicam também em aspectos subjetivos. A fim de contornar essa dificuldade, a presente discussão foi centrada na descrição das competências, a partir dos pressupostos de Perrenoud, confrontando com grau de dificuldade de atuação de competência " $G$ " (Figura $1)$.

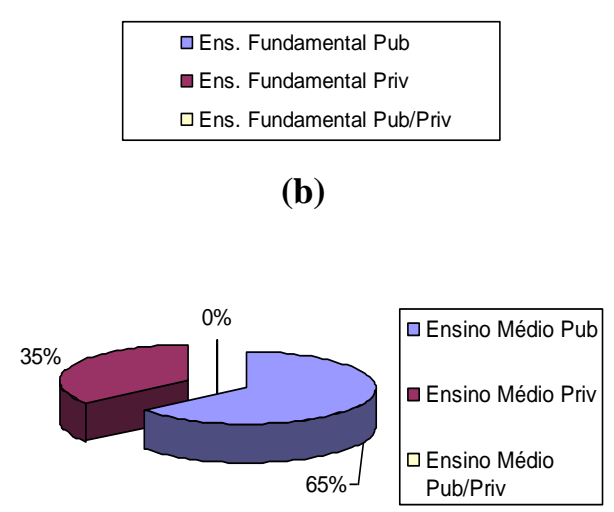

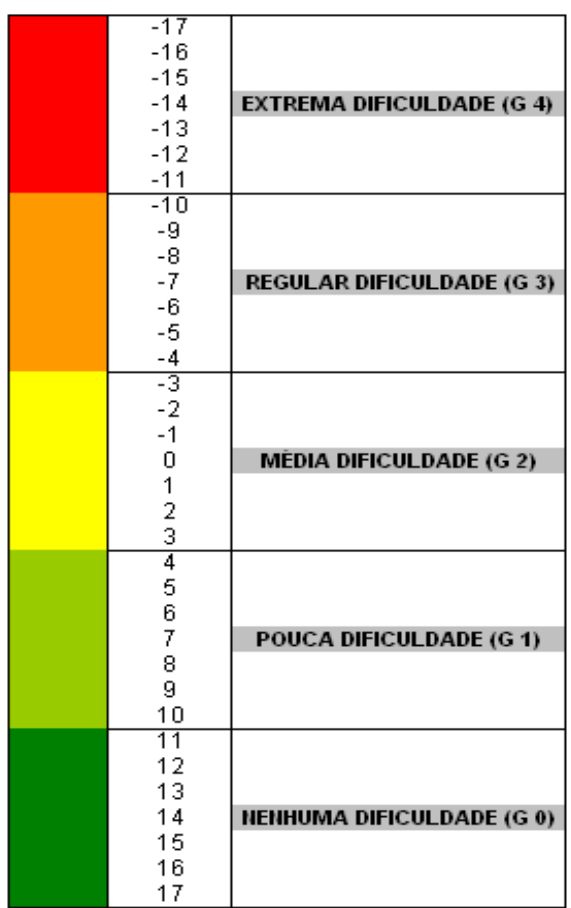

O Gráfico 3 apresenta basicamente o processo ensinoaprendizagem direto entre aluno e professor. Em termos de organizar e dirigir situações de aprendizagem, Gráfico 3a, foi revelado, com base nos desvios de -4 e -8 , que existe uma "Regular Dificuldade" em trabalhar a partir das representações dos alunos e construir, bem como planejar, disposi-

Gráfico 1. Formação Escolar: a) Ensino Fundamental; b) Ensino Médio; c) Ensino Superior e d) Pós-graduação Lato Sensu.
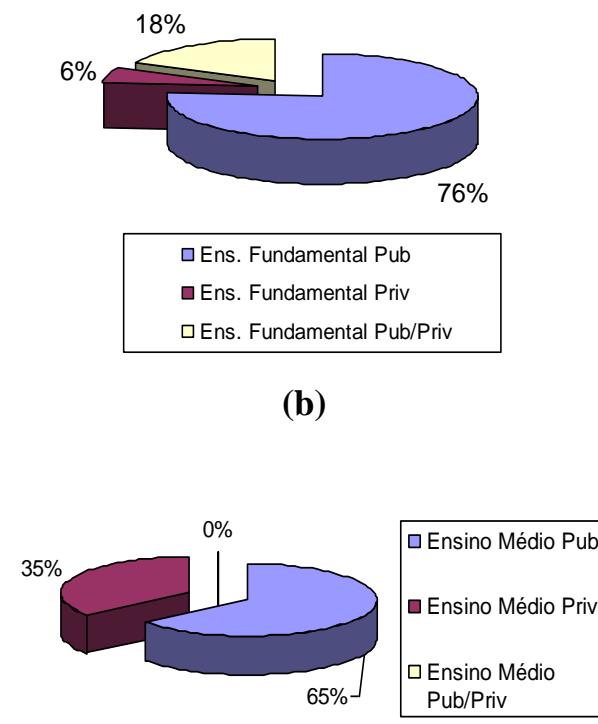

(b)

(a)

(c)

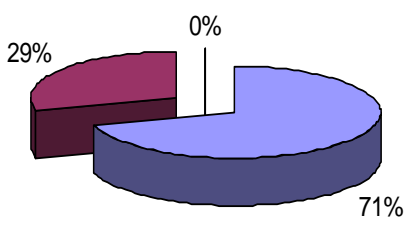

$\square$ Ensino Superior Pub Ensino Superior Priv $\square$ Ensino Superior Pub/Priv

(d)

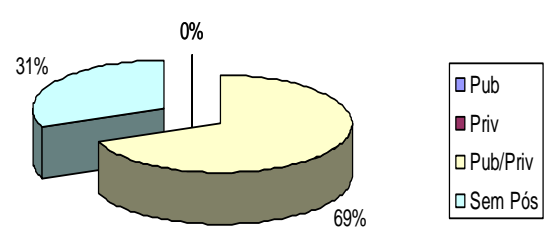

Fonte: próprios autores

tivos e sequências didática. $\mathrm{O}$ que foi percebido nesse estrato é que quando se fala de competência na esfera educacional, sabe-se que elas não podem ser vista exclusivamente numa perspectiva operacional de tarefas (DEPRESBITERIS, 2001, n. p.). É fun-

As competências pedagógicas na formação docente e profissional do pedagogo

damental verificar quais são as capacidades e conhecimentos que estão permitindo a mobilização das competências.

Gráfico 2. Caracterização da Formação Continuada dos professores pedagogos da EMCL.

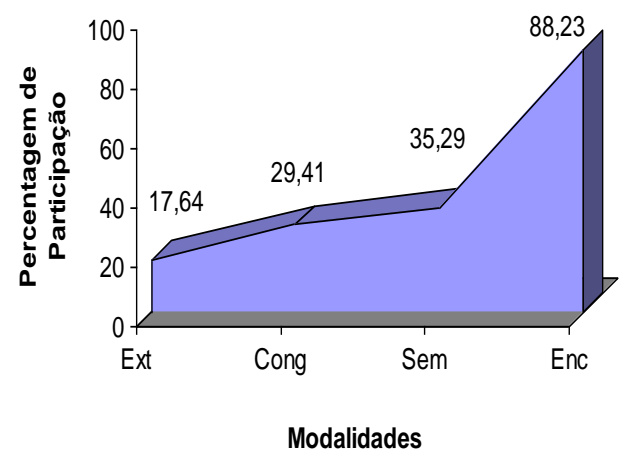

Fonte: próprios autores

Desse modo, buscou-se coletar informações da capacidade em administrar a progressão das aprendizagens, na qual foram verificados pequenos desvios negativos em se tratando da administração das situações problemas ajustadas ao nível e às possibilidades dos alunos (Gráfico $4 \mathrm{~b}$, 2A). Foram verificados pequenos desvios positivos para a observação e avaliação dos alunos em situação de aprendizagem (de acordo com uma abordagem formativa), bem como nos balanços periódicos de competências a fim de tomar decisões de progressão. A conformação desses resultados da Gráfico 10b mostrou o corpo docente com "Média Dificuldade".

O Gráfico 4a identifica a capacidade docente de fazer evoluir os dispositivos de diferenciação para o bom desenvolvimento da turma de alunos. Pletsch (2009) já chamava atenção para a capacidade de o professor assumir e sabe lidar com a diversidade existente entre os alunos, onde inclui o apoio e trabalho com os portadores de grandes dificuldades. 
com Ciência

Uma revista multidisciplinar
Quanto a isso o corpo docente apresentou "Pouca Dificuldade".

Gráfico 3. Desenvolvimento de competências: a) Organizar e dirigir situações de aprendizagem (1A) Trabalhar a partir das representações dos alunos; 1B) Trabalhar a partir dos erros e dos obstáculos à aprendizagem. 1C) Construir e planejar dispositivos e sequências didáticas) e b) Administrar a progressão das aprendizagens (2A) Conceber e administrar situações-problema ajustadas ao nível e às possibilidades dos alunos. 2B) Observar e avaliar os alunos em situações de aprendizagens, de acordo com uma abordagem formativa. 2C) Fazer balanços periódicos de competências e tomar decisões de progressão).

(a)

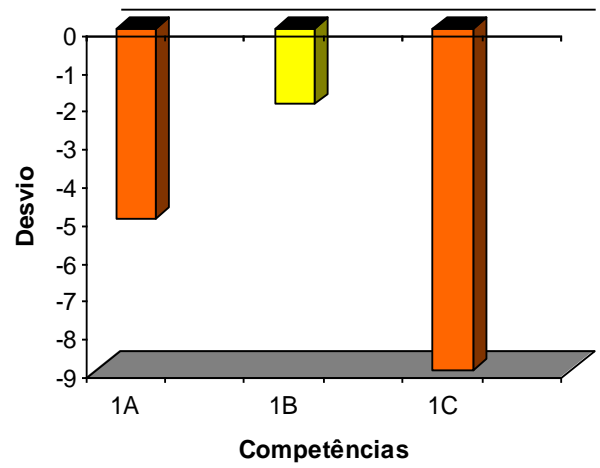

(b)

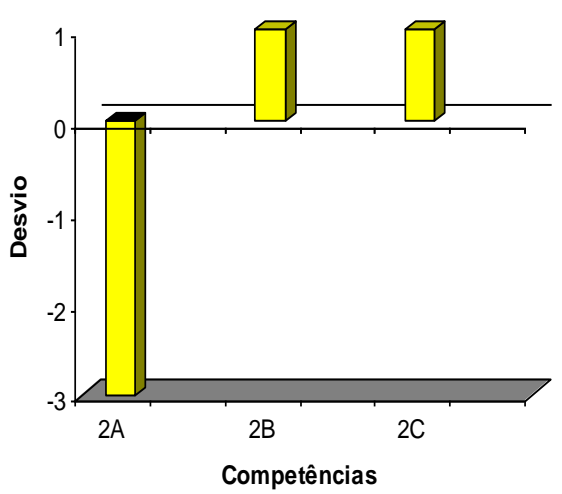

Fonte: próprios autores

A busca pelo envolvimento do aluno em sua aprendizagem e em seu trabalho encontrou mediana dificuldade no desenvolvimento no aluno da capacidade de auto-avaliação e no oferecimento de atividade opcionais de formação (Gráfico 4b, 4A e 4B).
Verificou-se que o favorecimento na definição de um projeto pessoal do aluno, Gráfico 4 (4C), mostrou-se com o grau G1 indicando que existe um equilíbrio no compromisso com o desempenho do aluno e com sua atuação no contexto fora do EMCL.

No quesito da competência de uso de novas tecnologias, Gráfico 5a, foi notado, que tanto a utilização de aplicativos comuns do ambiente Windows quanto exploração das potencialidades didáticas desses softwares aplicativos em relação aos objetivos do ensino obtiveram altos desvios positivos, 5A e 5B. Porém, existe uma contradição no uso de novas tecnologias, pois esses mesmo professores apresentaram uma média dificuldade, com dois graus qualitativos abaixo, passando de G0 para G2, em se tratando de utilização das ferramentas multimídia no ensino. Isto é, a preparação de aulas e execução dessas mesmas aulas, se valendo da ferramenta multimídia, não está condizendo com a facilidade no uso de novas tecnologias. Se esse quadro de competência continuar incoerente, entendese que virá um problema futuro, pois, a tendência atual é que o professor seja cada vez menos a única fonte de referência para o aluno, em todos os sentidos, seja conhecimento específico ou geral. Segundo Barbosa et al. (2000 p. 67) no paradigma educacional baseado em novas tecnologias da informação o professor interage com as fontes de informações da mesma forma que os alunos, uma vez que ambos tem acesso a novos conhecimentos com a mesma facilidade.

Gráfico 4. Desenvolvimento de competências: a) Conceber e fazer ouvir os dispositivos de diferenciação (3A) Administrar a heterogeneidade no âmbito de uma turma; 3B) Fornecer apoio integrado, trabalhar com alunos portadores de grandes dificuldades; 3C) Desenvolver a cooperação entre os alunos e certas formas simples de ensino mútuo e b) Envolver os alunos em sua aprendizagem e em seu trabalho (4A) Suscitar o desejo de aprender, explicar a relação com o saber, o sentido do trabalho escolar e desenvolver no aluno a capacidade de auto avaliação. 4B) Oferecer atividades opcionais de formação, à la carte. 4C) Favorecer a definição de um projeto pessoal do aluno

(a)

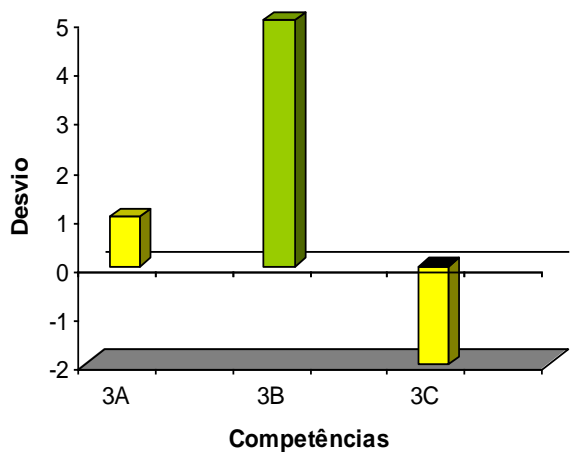

(b)

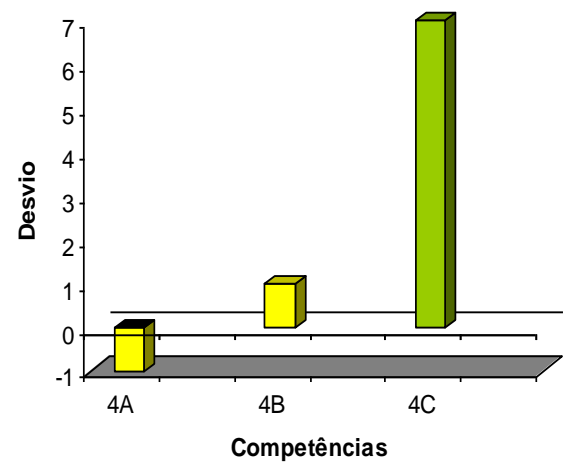

Fonte: próprios autores

No caso do Gráfico 6b que trata do enfrentamento dos deveres e dilemas éticos da profissão, todos os desvios foram negativos, e com grau G3 para a luta contra os preconceitos e discriminações sexuais, éticas e sociais, além do desenvolvimento do sen- 
com Ciêncio

Uma revista multidisciplinar so de responsabilidade, solidariedade e senso de justiça. Essa resposta comportamental cria uma dúvida quanto ao desempenho das competências na interação do professor docente com essa temática. $\mathrm{Na}$ realidade, é a falta de entender a competência como a capacidade de mobilizar os saberes dentro de uma perspectiva pedagógica com alcance no cotidiano. Hoje, a profissão já não é a transmissão de um conhecimento acadêmico ou a transformação do conhecimento comum do aluno em um conhecimento acadêmico. A profissão exerce outras funções: motivação luta contra a exclusão social, participação, animação de grupos, relações com estruturas sociais, com a comunidade (IMBERNÓN, 2001 p. 14).

Observando, ainda, o Gráfico 6 (8A) constata-se um limiar entre "Regular" e "Extrema Dificuldade" de os professores do EMCL desenvolverem trabalho em equipe. Isto é, dentre todas as atividades que são pertinentes a eles como docentes, existe esse grau de dificuldade em elaborar um projeto de equipe e administrar crises e conflitos interpessoais. A identificação desse problema é tão importante que Pimenta (1994 p. 80) alerta que o trabalho coletivo tem sido apontado por pesquisadores e estudiosos como o caminho mais profícuo para o alcance das novas finalidades da Educação Escolar, porque a natureza do trabalho na Escola - que é a produção do humano - é diferente da natureza do trabalho em geral na produção de outros produtos. Apesar desse alerta, quando se trata no envolvimento com os pais, a execução das tarefas indicou uma melhora no grau de dificuldade alcançando o desvio positivo de 5, com "Pouca Dificuldade" (Gráfico 6b, 8C).
Gráfico 5. Desenvolvimento de competências a) Utilizar novas tecnologias: (5A) Utilizar editores de textos; 5B) Explorar as potencialidades didáticas dos programas em relação aos objetivos de ensino; 5C) Utilizar as ferramentas multimídia no ensino e b) Enfrentar os deveres e os dilemas éticos da profissão: (6A) Prevenir a violência na escola e fora dela; 6B) Lutar contra os preconceitos e as discriminações sexuais, éticas e sociais; 6C) Desenvolver o senso de responsabilidade, a solidariedade e o sentimento de justiça).

(a)

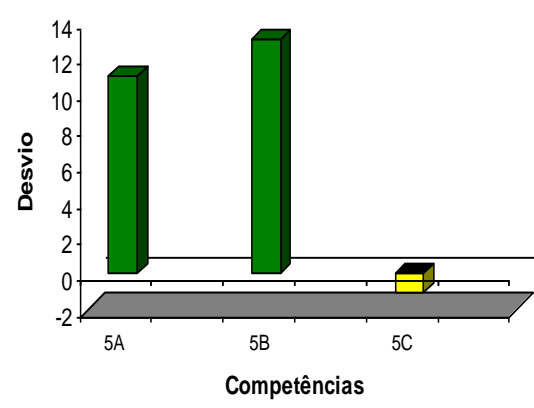

(b)

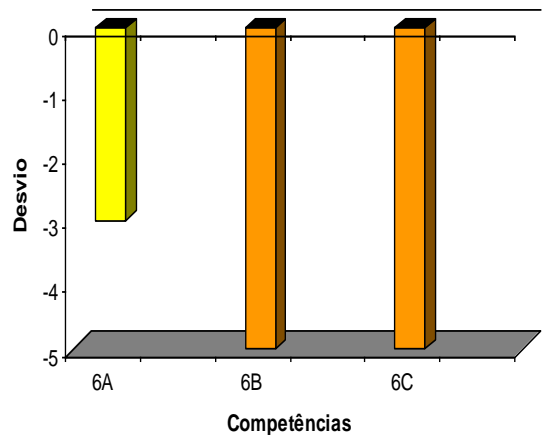

Fonte: próprios autores

Gráfico 6. Desenvolvimento de competências: a) Administrar sua própria formação contínua (7A) Estabelecer seu próprio balanço de competências e seu programa pessoal de formação contínua; 7B) Negociar um projeto de formação comum com os colegas (equipe, escola, rede).; 7C) Acolher a formação dos colegas e participar dela e b) Interação das Competências 5: (8A) Elaborar um projeto de equipe, representações comuns e Administrar crises ou conflitos interpessoais; 6 (8B) Elaborar, negociar um projeto da Instituição e 7 (8C) Envolver os pais na construção dos saberes. (a)

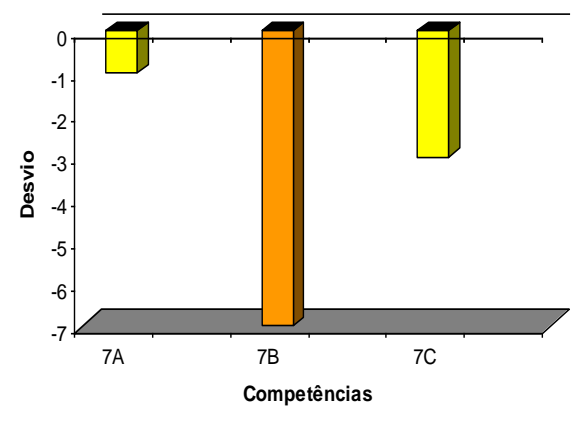

(b)

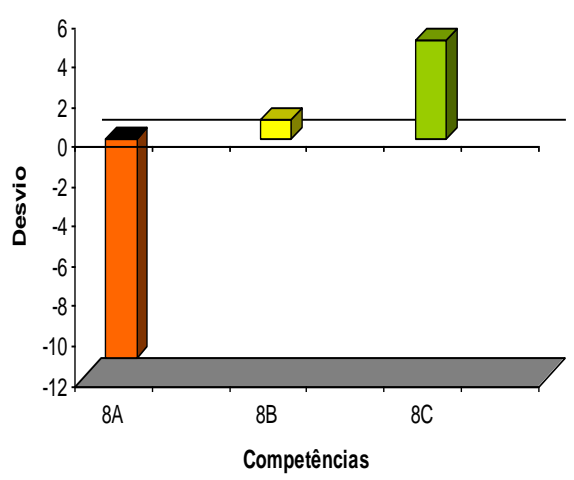

Fonte: próprios autores

Vislumbrando o Gráfico 7, onde se vê um diagnóstico do professor docente como ator no sistema, constatou-se que essa classe de competência mostrou resultados muito dicotômicos entre si, o que não condiz com a interação dos questionamentos dirigidos. Esse entrelaçamento da " $11^{\mathrm{a}}$ competência" tem por objetivo entender como o professor está formando o novo cidadão, ou melhor, o cidadão necessário. Segundo Pimenta (1994 p. 78) isso significa formá-lo com capacidade para se ter inserção social crítica/transformadora. Outro ponto a ser abordado é a relação inversa entre a alta participação em eventos na área de educação, que apresentou o grau de "Nenhuma Dificuldade" com a baixíssima produção científica que apresentou o grau de "Extrema Dificuldade" (Gráfico 7, 9C e 9D). Com base nessa 
com Ciência

Uma revista multidisciplinar contradição poderia se especular que a participação nesses eventos não está acrescentando muita inovação informacional que seja passível de reprodução pessoal.

Gráfico 7. Capacidade de ação como ator no sistema, na profissionalização, na prática reflexiva e do conhecimento/domínio das inovações (9A) Participação no movimento sindical; 9B) Participação na elaboração das reformas escolares (projeto); 9C) Participação em eventos na área de educação; 9D) Participação na produção científica (artigos).

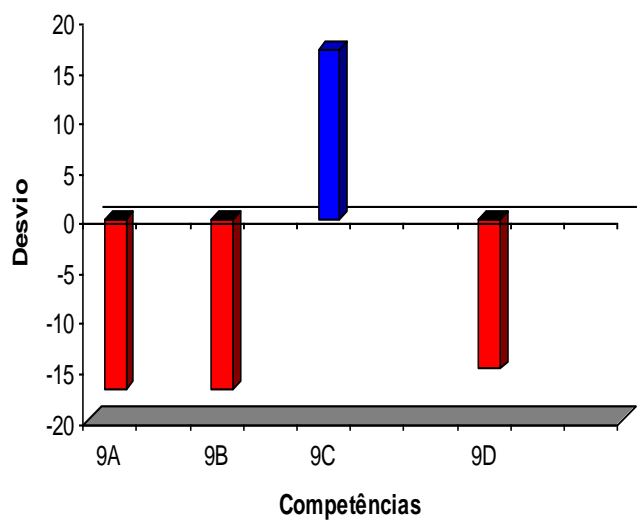

Fonte: próprios autores

Diante do mapa descritivo das dificuldades para desempenhar as competências, apresentado nos resultados anteriores, nota-se que os resultados trazem profundas consequências para o trabalho docente, e em especial no cumprimento do PPP (projeto político-pedagógico) visando melhorá-lo cada vez mais com o único intuito de garantia da qualidade do ensino no EMCL. Tacitamente, a melhoria do PPP teria o reconhecimento do pedagogo profissional, pois é resultado da construção coletiva dos atores da Educação Escolar. Ele é a tradução que a Escola faz de suas finalidades, a partir das necessidades que lhe estão colocadas, com o pessoalprofessores/alunos/equipe pedagógi$\mathrm{ca}$ /pais-e com os recursos de que dis- põe (PIMENTA, 1994 p. 79). O desconhecimento ou o desinteresse pelo vigente PPP já tinha sido diagnosticado indiretamente quando foi identificada uma "Média Dificuldade" na participação da gestão escolar (Gráfi$\cos 6 \mathrm{~b}, 8 \mathrm{~B})$ aliada a uma extrema dificuldade na participação em projetos de reforma escolar (Gráficos $7 \mathrm{e}$ 9B). A solidificação desse comportamento pode ser averiguada no Gráfico 8 onde mais da metade dos respondentes enquadram o PPP na condição de regular, e não demonstraram interesse de reformulá-lo. Atualmente, a Secretaria da Educação está solicitando de todas as unidades de ensino, do município de Barreiras, uma nova versão do PPP a fim de ajustar a tradução de cada escola, no que diz respeito a visão do ensino frente às novas tendências educacionais.

Gráfico 8. Avaliação dos docentes do Projeto Político Pedagógico do EMCL.

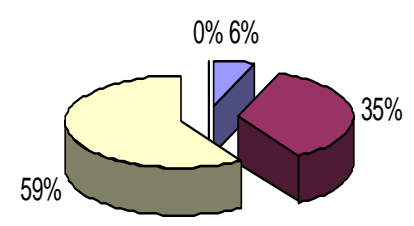

\begin{tabular}{|l|}
\hline$\square$ Ótimo \\
$\square$ Bom \\
$\square$ Regular \\
$\square$ Ruim \\
\hline
\end{tabular}

Fonte: próprios autores

\section{Considerações finais}

Após a análise dos resultados dos questionários aplicados, e dentro das condições trabalhadas pelo contorno metodológico, pode-se inferir que a falta de envolvimento com projetos de extensão pode ter condicionado a uma dificuldade de desenvolvimento nas competências 6B e 6C, constadas pelos altos desvios negativos atingindo o grau 3. Além disso, com grau no nível 3 (7B) o corpo docente não mostrou interação nos planejamentos comuns com os colegas de equipe e com a escola. Assim, não poderia se esperar um domínio no arcabouço da competência 9 (6B e 6C) que culminaram com a mesma resposta $\mathrm{G} 3$, pois é naturalmente derivada dessa competência;

Um ponto forte que se destaca na análise coletiva das competências foi a "Média Dificuldade" em administrar a progressão das aprendizagens (segunda competência). Isso significa que os professores buscaram uma intensa aproximação didática para entender as dificuldades de assimilação dos alunos;

Por fim, constatou-se um vácuo dentro da décima competência onde a formação pedagógica dos professores não se correlacionou com a missão institucional do CMCL, sendo tal fato corroborado por meio da visão medianamente negativa do PPP. Talvez a falta de envolvimento com o desenvolvimento das competências 5 (8A) e 11 (9B) tenha forjado esse cauterização negativa.

\section{Referências}

BARBOSA, E. F.; MARTINS, R. C.; ROCHA, M. F. A formação profissional da educação - perspectivas e desafios na educação profissional. Educação Tecnológica, v.5, n.2, p.62-70, 2000.

DEPRESBITERIS, L. Avaliando Competências na Escola de Alguns ou na Escola de todos?-Boletim Técnico do SENAC, Rio de Janeiro, V. 27, n. 3, 2001 .

IBGE - Instituto Brasileiro de Geografia e Estatística. Relatório Informações Estatísticas de Barreiras, Agência de Barreiras, 2017.

IMBERNÓN, F. Formação docente e profissional-Formar-se para a mu- 
dança e a incerteza. São Paulo, Cortez. 2001.

MACEDO, J. M. de. Reestruturação produtiva e políticas de formação de novas competências para o trabalho docente. Reunião Anual da ANPED, XXV, Caxambu (MG), 2002.

NÓVOA, A. Os Professores e sua Formação, Lisboa: Publicações Don Quixote, Ltda., 1992.

NUNES, C. M. F. Saberes docentes e formação de professores: um breve panorama da pesquisa brasileira. Educação e Sociedade. vol. 22, n.74, p.27-42, 2001.

PERES, M. R. et al. A formação docente e os desafios da prática reflexiva. Educação, Santa Maria, v. 38, n. 2, p. 289-304, maio/ago. 2013.

PERRENOUD, P. Dez novas competências para ensinar. Porto Alegre: Artmed, 2000.

PLETSCH, M. D. A formação de professores para a educação inclusiva: legislação, diretrizes políticas e resultados de pesquisas. Educar, Curitiba, n. 33, p. 143-156, 20009.

PIMENTA, S. G. Questões sobre a organização do trabalho na escola.

Revista CEAP Informa, n. 04, p.7883, Mar. 1994.

PIRES, K. C. P. Perfil do Professor do Curso de Graduação de Biologia na Universidade Estadual de Goiás Unidade Laranjeiras, não paginado, fev. 2009. Disponível em < http://www.webartigos.com/articles/1 4933/1/PERFIL-DO-PROFESSORDO-CURSO-DE-GRADUACAO-DEBIOLOGIA-NA-UNIVERSIDADEESTADUAL-DE-GOIAS--

UNIDADE-LARANJEIRAS/pagina1.html\#ixzz1Da1dMtal >. Acesso em: 20 de setembro de 2015 .

PERRENOUD, P. et al. Formando professores profissionais: Quais estratégias? Quais competências? trad. Fátima Murad e Eunice Gruman.-2 ${ }^{\mathrm{a}}$ ed.rev.- Porto Alegre: ARTMED Editora, 2001.

SENAC. Centro de Tecnologia e Gestão Educacional. Educação Profissional e Competências. Senac, SP. Março, 2002.

SILVA, R. de C. N. Estudo descritivo das competências pedagógicas necessárias considerando a formação docente e profissional do pedagogo: um estudo de caso na esfera municipal. Monografia (TCC em Pedagogia) Departamento de Ciências Humanas/Campus IX, Universidade do Estado da Bahia, Barreiras, 2009, 58p.

SILVA, A. M. C. A formação continua de professores: Uma reflexão sobre as práticas e as práticas de reflexão em formação. Educação \& Sociedade, n.72, p. 89-109, ago. 2002.

SILVEIRA, R. Competências e habilidades pedagógicas. Revista Iberoamericana de Educación, Madrid, v.1, n.31, p. 01-05, 2003.

SOARES, L. J. G. Educação de Jovens e Adultos: momentos históricos e desafios atuais. Presença Pedagógica. Belo Horizonte, n.11, p. 27-35 set/out 1996. 